\title{
Elaboração e análise sensorial de biscoito tipo cookie feito a partir da farinha do caroço de abacate
}

\section{Elaboration and sensory analysis of cookies made from avocado lump flour}

\author{
Igor Gondin da Silva ${ }^{1 *}$ (1), Ana Paula Colares de Andrade ${ }^{1}$, \\ Larissa Morais Ribeiro da Silva², Deyzilene Soares Gomes ${ }^{2}$ \\ ${ }^{1}$ Centro Universitário Estácio do Ceará, Curso de Nutrição, Fortaleza/CE - Brasil \\ ${ }^{2}$ Universidade Federal do Ceará (UFC), Departamento de Engenharia de Alimentos, Laboratório de Frutos \\ Tropicais, Fortaleza/CE - Brasil
}

*Corresponding Author: Igor Gondin da Silva, Centro Universitário Estácio do Ceará, Curso de Nutrição, Rua Um,

9, Nova Metrópole, CEP: 61659-000, Caucaia/CE - Brasil, e-mail: igorgondimss@gmail.com

Cite as: Silva, I. G., Andrade, A. P. C., Silva, L. M. R., \& Gomes, D. S. (2019). Elaboration and sensory analysis of cookies made from avocado lump flour. Brazilian Journal of Food Technology, 22, e2018209.

https://doi.org/10.1590/1981-6723.20918

\begin{abstract}
Resumo
Uma boa alternativa que vem sendo desenvolvida e aplicada nos últimos anos é o aproveitamento de resíduos oriundos do processamento de frutas e hortaliças. Grande parte do que é descartado dessas matérias-primas, tais como cascas, sementes e talos, pode ser reaproveitada na produção de novos alimentos. Este trabalho teve como objetivo desenvolver e avaliar a aceitação de biscoito tipo cookie elaborado a partir da farinha do caroço de abacate. Três formulações foram utilizadas no desenvolvimento do cookie: F1 (formulação do biscoito com acréscimo de 5\% da farinha do caroço de abacate); F2 (formulação do biscoito com acréscimo de $10 \%$ da farinha do caroço de abacate) e F3 (formulação do biscoito com acréscimo de $20 \%$ da farinha do caroço de abacate). Em seguida, os biscoitos foram avaliados sob o ponto de vista físico-químico (umidade, cinzas, lipídeos, proteínas, carboidratos e valor calórico) e sensorial (aceitabilidade dos atributos aparência, cor, textura e sabor, além da intenção de compra). Entre as formulações testadas, a F1 (formulação do biscoito com acréscimo de $5 \%$ da farinha do caroço de abacate) foi mais bem aceita pelos provadores, visto que apresentou as maiores notas nos atributos sensoriais avaliados e uma intenção de compra acima da média (70\%). Dessa forma, este estudo demonstrou a importância do aproveitamento integral de resíduos provenientes do processamento de produtos de origem vegetal no desenvolvimento de um novo produto, que apresenta potencial para a comercialização e um maior valor nutricional.
\end{abstract}

Palavras-chave: Tecnologia de alimentos; Subproduto; Composição nutricional; Valor nutritivo; Alimento funcional; Análise de alimentos.

\begin{abstract}
A good alternative that has been developed and applied in recent years is the use of residues from the processing of fruits and vegetables. Much of what is discarded from raw materials such as peels, seeds and stems can be reused in the production of novel foods. The objective of this work was to develop and evaluate the acceptance of cookie elaborated from avocado lump flour. Three formulations were used in the cookie development: F1 (biscuit
\end{abstract}


formulation added with $5 \%$ of avocado lump flour); F2 (biscuit formulation added with $10 \%$ of avocado lump flour); and F3 (biscuit formulation added with $20 \%$ of avocado lump flour). After elaboration, cookies were evaluated for physical-chemical characteristics (moisture, ashes, lipids, proteins, carbohydrates and caloric value) and sensorial characteristics (acceptability of appearance, color, texture and taste attributes, besides purchase intention). Among the formulations tested, F1 (biscuit formulation added with $5 \%$ of avocado lump flour) was well accepted by the tasters, since it presented the highest scores on the sensorial attributes evaluated and an above-average purchase intention (70\%). Thus, this study demonstrated the importance of the integral use of residues from the processing of plant originated products in new products development, with potential for commercialization and a higher nutritional value.

Keywords: Food technology; Residues; Nutrition composition; Nutritional value; Functional food; Food analysis.

\section{Introdução}

Diversos setores da sociedade têm concentrado seus esforços em buscar meios de tornarem compatíveis os ritmos de crescimento econômico e de produção, com a manutenção e a preservação da qualidade ambiental e dos recursos naturais, materiais e energéticos, bem como a saúde e a segurança do trabalhador e da comunidade (Menezes, 2013).

Uma alternativa que vem ganhando notoriedade ao longo dos últimos anos é o aproveitamento integral e/ou parcial de resíduos não utilizados de frutas e hortaliças. Grande parte do que é descartado, como cascas, sementes e talos, pode ser aproveitada na produção de novos alimentos, contribuindo, assim, para o combate à desnutrição e à fome (Galindo, 2014).

Além de ajudar na redução de custos das preparações alimentícias e na diminuição nos índices de desperdício de alimentos, o aproveitamento de partes não utilizáveis desses alimentos pode contribuir para a melhoria da ingestão de nutrientes pela população, tornando possível elaborações de novas receitas e preparações. Segundo Storck et al. (2013), as frutas que mais apresentam perdas durante o processamento são o abacate (31\%), a banana (40\%) e o morango (39\%).

Em relação ao abacate, o fruto se destaca sob o ponto de vista nutricional por causa da grande quantidade de ácidos graxos monoinsaturados presente em sua composição, com destaque para o ácido oleico (ômega 9). Apesar de apresentar um valor calórico maior que as demais frutas, sua polpa contém inúmeras vitaminas e minerais, com destaque para o potássio e a vitamina $\mathrm{E}$, o que torna seu consumo interessante nas preparações destinadas à dieta humana (Ferrari, 2015). O alto teor de fibras presente no fruto permite a utilização de partes normalmente não comestíveis para o desenvolvimento de novos produtos voltados para alimentação, tais como farinhas, biscoitos, pães e massas alimentícias (Chaves et al., 2013).

Diante do exposto e das várias alternativas relacionadas à utilização do abacate, principalmente para fins alimentares, este trabalho teve como objetivo desenvolver e avaliar sensorialmente um biscoito tipo cookie elaborado a partir da farinha do caroço de abacate.

\section{Material e métodos}

\subsection{Matéria-prima}

Os abacates foram obtidos no mercado local de Fortaleza, Ceará, selecionados de acordo com homogeneidade de tamanho, peso, intensidade da cor da casca e firmeza, sendo armazenados à temperatura ambiente até o processamento da farinha.

Os ingredientes utilizados nas formulações para a produção dos biscoitos tipo cookie foram: farinha de trigo com fermento, farinha do caroço de abacate, margarina, açúcar cristal, açúcar mascavo, bicarbonato de 
sódio, ovo, aveia em flocos e essência de baunilha. Todos os ingredientes foram obtidos em estabelecimentos comerciais das cidades de Fortaleza e Caucaia, no Ceará.

\subsection{Elaboração da farinha do caroço de abacate e dos biscoitos cookies}

O processamento da farinha do caroço de abacate foi composto, principalmente, das etapas de higienização, descasque, corte, retirada do caroço, tratamento e acondicionamento, de acordo com o fluxograma apresentado na Figura 1.

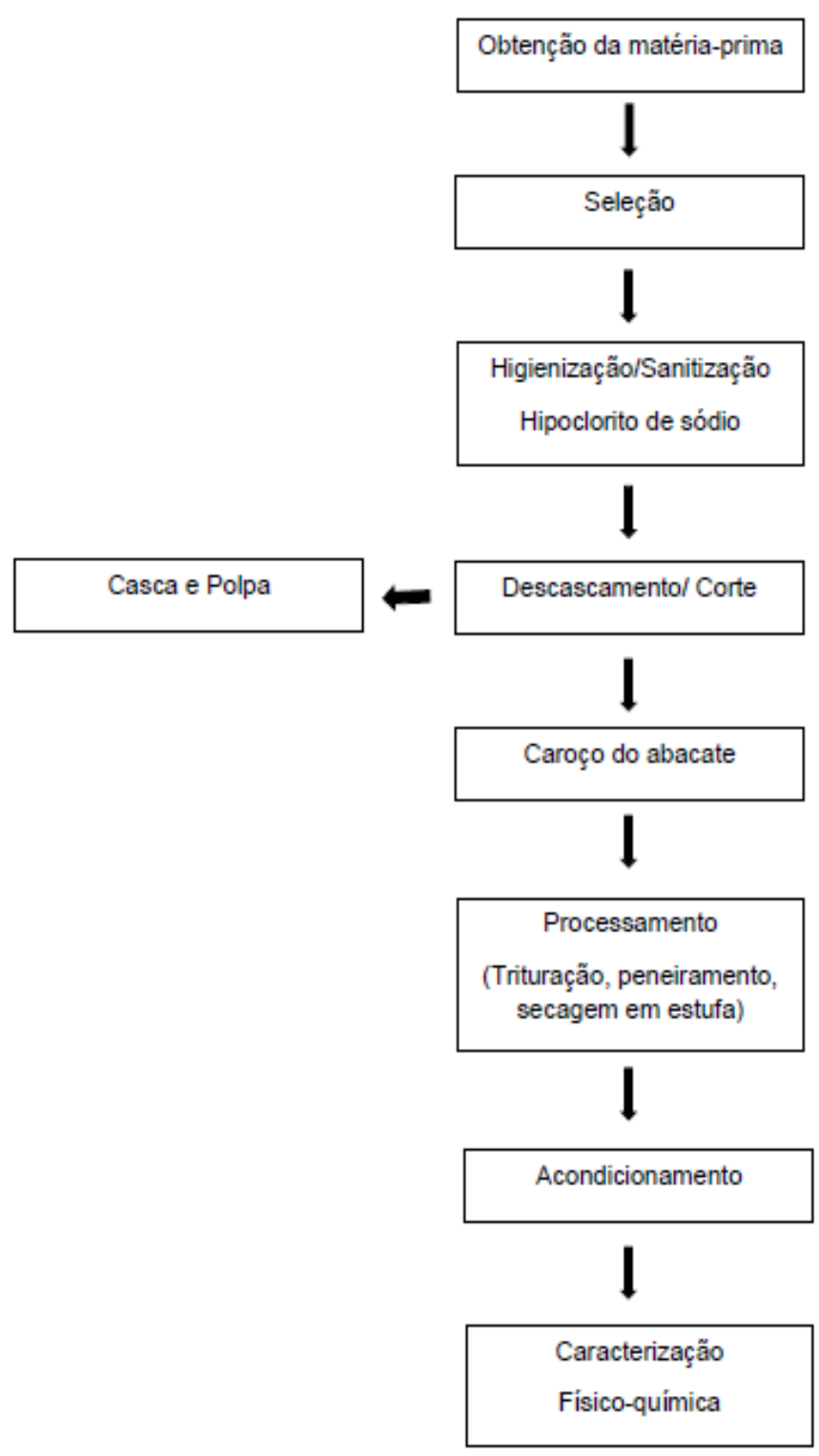

Figura 1. Fluxograma das etapas realizadas para a obtenção da farinha a partir do caroço de abacate.

A elaboração da farinha do caroço de abacate e das formulações dos biscoitos tipo cookie foi desenvolvida no Laboratório de Técnica e Dietética e Tecnologia de Alimentos do Centro Universitário Estácio do Ceará, unidade Via Corpvs, com base na composição de Rigo et al. (2017) adaptada para substituição parcial da farinha de trigo pela farinha do caroço de abacate. As formulações estão apresentadas na Tabela 1. 
Tabela 1. Formulações utilizadas na elaboração de biscoitos tipo cookie feitos a partir da farinha do caroço de abacate.

\begin{tabular}{cccc}
\hline Ingredientes & \multicolumn{3}{c}{ Formulações $^{\mathbf{1}}$} \\
\cline { 2 - 4 } & F1 & F2 & F3 \\
\hline Farinha do caroço de abacate $(\mathrm{g})$ & 6 & 12 & 24 \\
Farinha de trigo $(\mathrm{g})$ & 114 & 108 & 96 \\
Bicarbonato de sódio $(\mathrm{g})$ & 15 & 15 & 15 \\
Margarina $(\mathrm{g})$ & 120 & 120 & 120 \\
Açúcar cristal $(\mathrm{g})$ & 70 & 70 & 70 \\
Açúcar mascavo $(\mathrm{g})$ & 70 & 70 & 1 \\
Ovos (unidade) & 1 & 1 & 5 \\
\hline Essência de baunilha $(\mathrm{mL})$ & 5 & 5 & 15 \\
\hline Aveia em flocos $(\mathrm{g})$ & 15 & 15 & 15 \\
\hline
\end{tabular}

${ }^{1}$ F1 (formulação do biscoito com acréscimo de 5\% da farinha do caroço de abacate). F2 (formulação do biscoito com acréscimo de $10 \%$ da farinha do caroço de abacate). F3 (formulação do biscoito com acréscimo de $20 \%$ da farinha do caroço de abacate).

Inicialmente, todos os ingredientes foram separados e pesados. Em seguida, foram misturados em uma tigela a margarina, o açúcar cristal, o açúcar mascavo e a essência de baunilha. Aos poucos, foram sendo acrescentadas a farinha de trigo e a farinha do caroço de abacate, misturando em velocidade média, até obtenção de consistência cremosa. Por último, foram adicionados o ovo batido, o bicarbonato de sódio e a aveia em flocos, até a homogeneidade completa dos ingredientes.

A massa foi deixada em descanso, sob refrigeração $\left(10^{\circ} \mathrm{C}\right)$, por 45 minutos para formação da sua estrutura. A moldagem dos cookies foi realizada manualmente, dimensionando o tamanho de cada biscoito, com quantidade aproximada de 15 gramas (Queiroz et al., 2017). Os cookies foram dispostos em bandeja de alumínio revestida com papel-manteiga, mantendo uma distância de aproximadamente $5 \mathrm{~cm}$ entre eles, e, em seguida, submetidos ao processo de forneamento por 15 minutos, em forno elétrico pré-aquecido a $200{ }^{\circ} \mathrm{C}$ (Moura et al., 2010). Depois de assados, os biscoitos foram resfriados à temperatura ambiente, acondicionados e armazenados em embalagens de polietileno até a realização das análises físico-química e sensorial.

\subsection{Análises físico-químicas}

A farinha do caroço de abacate e as formulações de biscoitos tipo cookie foram submetidas a análises físico-químicas de acordo com as normas do Instituto Adolfo Lutz (2008).

A determinação da umidade foi realizada pelo método de secagem em estufa por 6 horas a $105^{\circ} \mathrm{C}$; o teor de proteínas, pelo método de Kjeldahl; o teor de lipídeos, pelo método adaptado de Bligh-Dyer; o teor de cinzas, por incineração em forno mufla por 18 horas a $550^{\circ} \mathrm{C}$ a $570{ }^{\circ} \mathrm{C}$; o teor de carboidratos, por diferença, isto é, 100 menos a somatória das frações de proteínas, lipídeos, cinzas e umidade (Cecchi, 2003). As análises de composição centesimal foram realizadas em três repetições, para cada formulação.

O valor energético total em $100 \mathrm{~g}$ de cada cookie foi determinado segundo os valores calóricos estimados da conversão de Atwater, multiplicando-se o valor de carboidratos disponíveis e de proteínas por quatro e o de lipídeos por nove. A soma dos produtos constituiu o valor energético total (Osborne \& Voogt, 1986).

\subsection{Análise sensorial}

A análise sensorial foi realizada no Laboratório de Análise Sensorial do Centro Universitário Estácio do Ceará, unidade Via Corpvs. Participaram dessa análise 70 provadores, não treinados, considerados consumidores potenciais do produto, caracterizados quanto ao gênero, à idade, e ao curso, que assinaram o Termo de Consentimento Livre e Esclarecido (TCLE). O estudo foi aprovado pelo Comitê de Ética em Pesquisa do Centro Universitário Estácio do Ceará sob Parecer nº 2.857.904. 
As amostras foram apresentadas aos provadores de forma aleatória, à temperatura ambiente, em pratos descartáveis e codificados com número de três dígitos escolhidos aleatoriamente. Os provadores estavam posicionados em cabines individuais e foram devidamente orientados a observar as características do produto e o preenchimento das fichas de respostas. Um copo de água mineral foi oferecido entre as amostras para eliminar o sabor residual na boca (Queiroz et al., 2017).

Aplicou-se o teste sensorial de ordenação por preferência, em que as três amostras foram apresentadas aos provadores, os quais organizaram em uma ficha de avaliação sua preferência, na qual 1 representava "menos preferida", e 3, "mais preferida" (Dutcosky, 2013). A amostra preferida teve seus atributos sensoriais (aparência, cor, textura e sabor) avaliados utilizando escala hedônica estruturada de 9 pontos, em que 9 representava "gostei extremamente", e 1, "desgostei extremamente" (Instituto Adolfo Lutz, 2008). Além disso, avaliou-se a intenção de compra do biscoito formulado por meio de escala estruturada de 5 pontos, em que 5 representava "certamente compraria", e 1, "certamente não compraria" (Instituto Adolfo Lutz, 2008).

\subsection{Análise estatística}

Os resultados obtidos foram tabulados em planilha do programa Excel (Microsoft Office 2015@), submetidos à análise de variância (ANOVA), seguida do teste de Tukey com nível de significância de 5\%, por meio do programa estatístico ASSISTAT, versão 7.6 beta (2013).

\section{Resultados e discussão}

\subsection{Análise físico-química}

Realizou-se, inicialmente, a caracterização físico-química da farinha do caroço de abacate, visto que esta foi utilizada como matéria-prima para a elaboração dos cookies (Tabela 2).

Tabela 2. Caracterização físico-química da farinha do caroço de abacate utilizada na elaboração dos cookies.

\begin{tabular}{cc}
\hline Parâmetros avaliados & Teor $^{\mathbf{1}} \mathbf{( \% )}$ \\
\hline Umidade & $27,55 \pm 0,12$ \\
Cinzas & $1,27 \pm 0,08$ \\
Lipídeos & $8,73 \pm 0,14$ \\
Proteínas & $5,17 \pm 0,38$ \\
Carboidratos totais & $57,28 \pm 0,03$ \\
Valor energético & $328,37 \mathrm{kcal}$ \\
\hline
\end{tabular}

${ }^{1}$ Resultados apresentados em valores médios \pm desvio padrão. ${ }^{2}$ Valor teórico.

Constatou-se que a farinha do caroço de abacate é de alta higroscopicidade (27,55\%). Esse valor diverge do estabelecido pela Agência Nacional de Vigilância Sanitária (ANVISA), a qual preconiza o valor máximo de até $15 \%$ de umidade para farinha. Resultado diferente foi encontrado por Silva et al. (2012), que constataram um teor de umidade de 10,06\% para a farinha elaborada a partir do resíduo de acerola.

De acordo com Almeida (2016), o parâmetro umidade pode ser considerado de grande relevância, visto que o teor de água é o principal fator para a proliferação de microrganismos. Teores de umidade menores favorecem a qualidade e a vida de prateleira do produto.

O teor de cinzas encontrado na farinha foi de 1,27\%. Esse resultado está de acordo com a legislação brasileira, que determina um teor máximo de $2 \%$ em base seca para farinhas. Entretanto, Nascimento et al. (2016) fizeram a caracterização físico-química da farinha do caroço de abacate e obtiveram um teor de cinzas de $2,2 \%$.

O teor de lipídeos encontrado $(8,73 \%)$ foi duas vezes superior ao resultado obtido na análise de lipídeos da farinha do caroço de abacate, realizada por Guimarães \& Capobiango (2017), que foi de 3,03\%. 
Observou-se que a quantidade de proteínas presente na farinha do caroço de abacate foi de 5,17\% Esse resultado é superior ao apresentado por Nascimento et al. (2016) e Guimarães \& Capobiango (2017), que encontraram valores de 4,57\% e 3,34\%, respectivamente. Em outro estudo, Tango et al. (2004) avaliaram o teor de proteínas em 24 tipos de variedade de abacate e constataram que o teor proteico, dependendo da variedade da fruta, pode variar entre $3,78 \%$ e $6,7 \%$.

O teor de carboidratos totais $(57,28 \%)$ da farinha do caroço de abacate foi relativamente menor do que os resultados apresentados no estudo realizado por Nascimento et al. (2016), que foi de 63,80\%

Algumas pesquisas demonstraram que a diferença entre os valores dos macronutrientes entre os estudos pode estar correlacionada com alguns fatores, tais como os níveis de maturação do fruto, o tamanho do fruto e a variedade do abacate utilizado nas pesquisas (Nascimento et al., 2016; Almeida, 2016; Guimarães \& Capobiango, 2017).

\subsubsection{Composição nutricional dos cookies}

Na Tabela 3, estão apresentados os resultados da análise de composição centesimal dos cookies elaborados. O percentual de umidade variou significativamente $(p<0,05)$ entre as formulações $(13,87 \%$ a $18,44 \%)$, em que, se constatou que os menores teores de umidade estavam presentes nas formulações com maiores percentuais da farinha do caroço de abacate (F2 e F3), corroborando a Resolução RDC n ${ }^{\circ} 263$, de 22 de setembro de 2005 da ANVISA, que preconiza que a umidade de biscoitos e bolachas deve ser de no máximo $14 \% \mathrm{p} / \mathrm{p}$ (Brasil, 2005).

Tabela 3. Caracterização físico-química de biscoitos tipo cookie em três diferentes formulações, feitos a partir da farinha do caroço de abacate.

\begin{tabular}{cccc}
\hline \multirow{2}{*}{ Parâmetros avaliados } & F1 & Teor $^{\mathbf{1 , 2}} \mathbf{( \% )}$ & F3 \\
\cline { 2 - 4 } & $18,44 \pm 0,01$ & $14,04 \pm 0,01$ & $13,87 \pm 0,01$ \\
\hline Umidade & $2,73 \pm 0,01$ & $3,74 \pm 0,001$ & $2,6 \pm 0,005$ \\
Cinzas & $8,0 \pm 0,01$ & $9,40 \pm 0,01$ & $17,3 \pm 0,001$ \\
Lipídeos & $9,46 \pm 0,42$ & $8,82 \pm 0,1$ & $7,79 \pm 0,07$ \\
Proteínas & $61,37 \pm 0,44$ & $64,00 \pm 0,11$ & $58,44 \pm 0,02$ \\
Carboidratos totais & $355,32 \pm 0,89$ & $375,88 \pm 0,23$ & $420,62 \pm 0,10$ \\
Valor energético $(\mathrm{kcal})^{3}$ & &
\end{tabular}

${ }^{1} \mathrm{~F} 1$ (formulação do biscoito com acréscimo de $5 \%$ da farinha do caroço de abacate). F2 (formulação do biscoito com acréscimo de $10 \%$ da farinha do caroço de abacate). F3 (formulação do biscoito com acréscimo de $20 \%$ da farinha do caroço de abacate). ${ }^{2}$ Resultados apresentados em valores médios \pm desvio padrão. ${ }^{3}$ Valor teórico.

O baixo teor de umidade na formulação F1 pode ser justificado pelo baixo percentual de farinha de abacate acrescido na formulação de biscoitos. Soares et al. (2017) relataram que elevados teores de fibras, como os encontrados nas formulações F2 e F3, podem contribuir para uma maior retenção de água nos produtos.

O teor de cinzas das formulações analisadas variou entre $2,60 \%$ e $3,74 \%$. Portanto, observou-se que, quanto maior a quantidade de farinha do caroço de abacate utilizada para a formulação, maior o conteúdo de cinzas encontrado, corroborando um estudo feito por Queiroz et al. (2017), ao elaborarem cookies sem glúten com adição farinha de coco.

Observou-se que o teor de lipídeos encontrados nos cookies variou de 8\% a 17,3\%. Entretanto, na formulação F3 (que continha $20 \%$ da farinha do caroço de abacate), constatou-se a maior concentração de lipídeos. Segundo Chaves et al. (2013), tal fator pode estar relacionado ao grau de acidez presente no fruto, pois, quanto maior o grau de acidez, mais alto o teor lipídico.

O teor de carboidratos foi significamente maior em relação aos resultados encontrados em pesquisa desenvolvida por Chaves et al. (2013), na elaboração de biscoito integral utilizando óleo e farinha da polpa de abacate, em que, sua formulação com $10 \%$ da farinha da polpa de abacate apresentou $43,75 \%$ de carboidratos totais, enquanto, no presente estudo, a formulação com $10 \%$ da farinha do caroço de abacate resultou em 64\% de carboidratos totais. Segundo Melo et al. (2012), o teor de carboidrato do caroço de 
abacate é superior ao da polpa do fruto. O valor calórico total médio das formulações analisadas foi de 383,94 kcal.

\subsection{Análise sensorial}

$\mathrm{Na}$ Figura 2, estão expressos os valores em percentuais, segundo o teste de ordem de preferência. Verificou-se que a formulação com adição de 5\% da farinha do caroço de abacate (F1) foi a mais bem aceita entre os provadores, resultando em $58 \%$ de aprovação, seguida da formulação com adição de $10 \%$ da farinha do caroço de abacate (F2), que obteve $30 \%$ da preferência do público em questão.

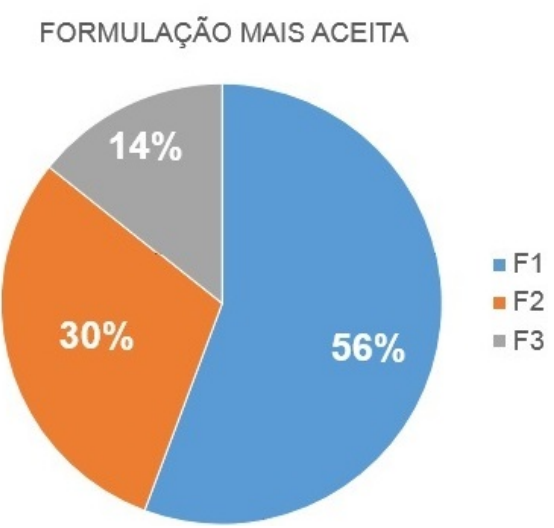

Figura 2. Ordem de preferência segundo os provadores para os cookies elaborados com a farinha do caroço de abacate. (F1) formulação do biscoito com acréscimo de 5\% da farinha do caroço de abacate; (F2) formulação do biscoito com acréscimo de $10 \%$ da farinha do caroço de abacate; (F3) formulação do biscoito com acréscimo de $20 \%$ da farinha do caroço de abacate.

Em contrapartida, a formulação com acréscimo $20 \%$ da farinha do caroço de abacate em relação à farinha de trigo (F3) foi a menos aceita entre os provadores (14\%), o que corrobora os resultados dos testes de aceitabilidade e intenção de compra, apresentados na Tabela 4 e na Figura 3.

Quanto ao teste de aceitabilidade, verificou-se que os atributos aparência, cor, e textura para todas as formulações foram bem aceitas pelos provadores, apresentando médias hedônicas entre 6 ("gostei ligeiramente") e 7,8 ("gostei regularmente"), com exceção ao atributo sabor para a formulação F3, em que se, constatou a média hedônica de 4,6 ("desgostei ligeiramente"). Isso pode ser explicado por causa do sabor residual amargo da farinha do caroço de abacate.

Tabela 4. Média e desvio padrão de aceitabilidade sensorial de biscoitos tipo cookie em três diferentes formulações, feitos a partir da farinha do caroço de abacate.

\begin{tabular}{|c|c|c|c|c|}
\hline \multicolumn{5}{|c|}{ Atributos sensoriais } \\
\hline Formulações ${ }^{1}$ & Aparência & Cor & Textura & Sabor \\
\hline $\mathrm{F} 1$ & $7.49^{a} \pm 1,3$ & $7.64^{a} \pm 1,2$ & $7.5^{\mathrm{a}} 4 \pm 1,1$ & $7.1^{\mathrm{a}} \pm 1,8$ \\
\hline $\mathrm{F} 2$ & $6.84^{\mathrm{a}, \mathrm{b}} \pm 1,6$ & $6.94^{\mathrm{a}, \mathrm{b}} \pm 1,5$ & $7.15^{\mathrm{a}} \pm 1,5$ & $6.59^{a} \pm 1,8$ \\
\hline $\mathrm{F} 3$ & $6.59^{b} \pm 1,9$ & $6,87^{\mathrm{b}} \pm 1,6$ & $6.04^{b} \pm 1,8$ & $4.51^{b} \pm 2,2$ \\
\hline
\end{tabular}

${ }^{1} \mathrm{~F} 1$ (formulação do biscoito com acréscimo de $5 \%$ da farinha do caroço de abacate). F2 (formulação do biscoito com acréscimo de $10 \%$ da farinha do caroço de abacate). F3 (formulação do biscoito com acréscimo de $20 \%$ da farinha do caroço de abacate). Médias seguidas da mesma letra minúscula nas colunas não diferem estatisticamente pelo teste de Tukey a 0,05 de significância.

Estudo realizado por Rosa et al. (2017), com a elaboração de cookies adicionados à farinha da casca da batata, demonstrou que a formulação com maior concentração da farinha da casca da batata $(13,5 \%)$ apresentou menor índice sensorial $(4,78 \pm 0,26)$, o que pode ser justificado pela presença de compostos voláteis presentes na casca de batata, como os álcoois alifáticos e os aldeídos, que podem alterar as características sensoriais dos produtos. 
Outra alteração tecnológica observada está relacionada à cor dos cookies, os quais ficaram mais escuros à medida que a concentração de farinha do caroço de abacate aumentava. Essa característica pode ser justificada pela elevada quantidade de carboidratos presentes nas formulações, as quais, quando submetidas ao forneamento, podem ter sofrido tanto o processo de caramelização quanto o de reação de Maillard, o que causou uma coloração mais escura dos produtos.

Segundo Lermen et al. (2013), os atributos aparência e sabor são as características mais importantes que podem influenciar as propriedades sensoriais de produtos alimentícios adicionados a ingredientes diferenciados, como a farinha do caroço de abacate.

Cabe ressaltar que os biscoitos poderão ter seu sabor aprimorado tecnologicamente pelo uso de edulcorantes naturais e/ou artificiais, melhorando, assim, esse atributo sensorial (Rodrigues et al., 2014).

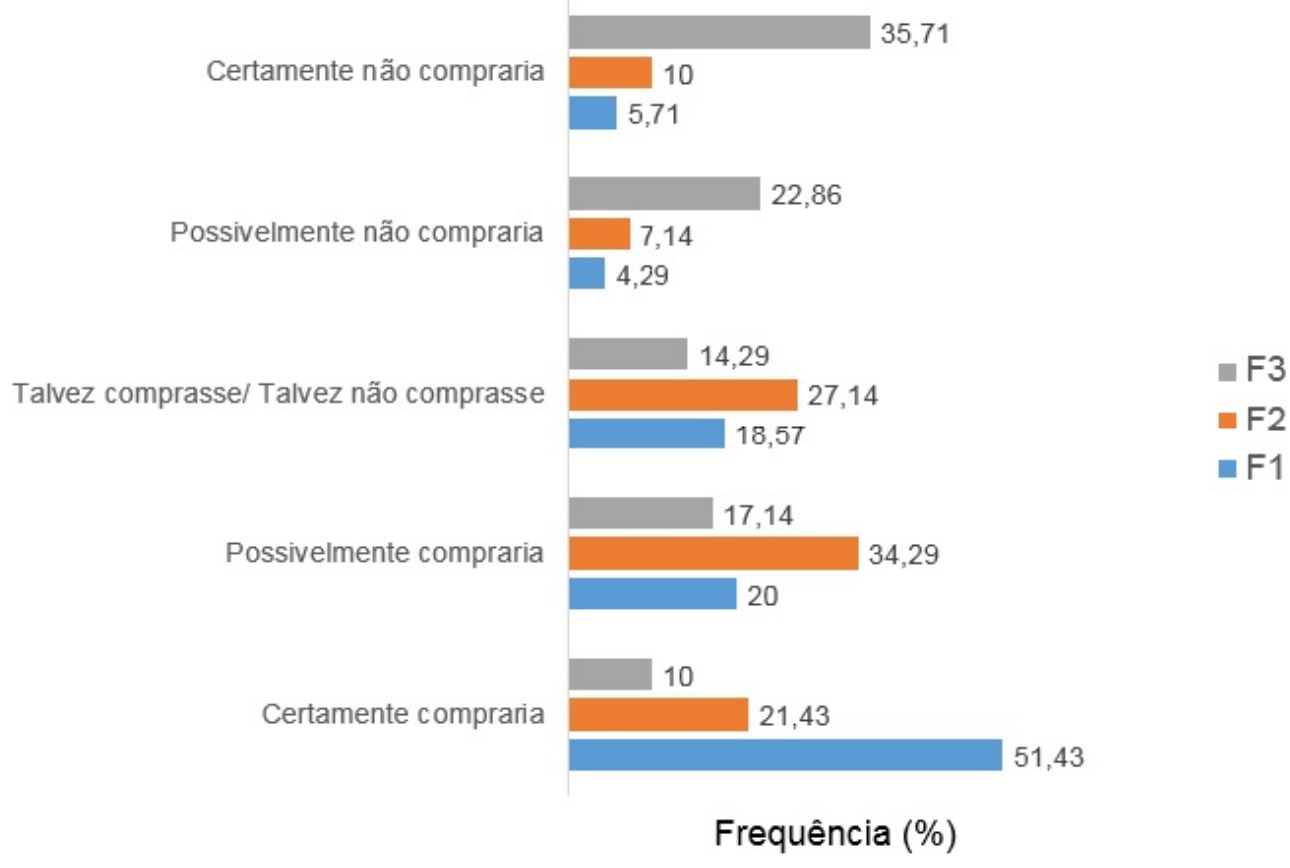

Figura 3. Intenção de compra dos provadores para os cookies elaborados com a farinha do caroço de abacate. (F1) formulação do biscoito com acréscimo de 5\% da farinha do caroço de abacate; (F2) formulação do biscoito com acréscimo de $10 \%$ da farinha do caroço de abacate; (F3) formulação do biscoito com acréscimo de $20 \%$ da farinha do caroço de abacate.

Quanto à intenção de compra, os provadores expressaram uma atitude positiva, caso os cookies com adição de 5\% (F1) e 10\% (F2) de farinha do caroço de abacate estivessem disponíveis no mercado (Figura 3).

O percentual positivo deu-se pela somatória das categorias "provavelmente compraria" e "certamente compraria". Cerca de $70 \%$ dos provadores declararam que comprariam os cookies da formulação F1, seguidos de $58 \%$ de aprovação de compra para formulação F2. Visto que o índice de aceitação deve ser igual ou superior a $70 \%$ para ser considerado satisfatório, o produto elaborado no presente estudo pode ser considerado passível de comercialização (Carmo et al., 2017).

\section{Conclusão}

A farinha do caroço de abacate apresentou características físico-químicas que favoreceram o seu uso em formulações alimentícias e contribuíram para o desenvolvimento de um novo produto. Observou-se que os cookies elaborados com o acréscimo de $5 \%$ da farinha do caroço de abacate em substituição à farinha de trigo (F1) destacaram-se por apresentar uma boa aceitação sensorial e uma intenção de compra acima da média, 
evidenciando que a incorporação da farinha de caroço do abacate permitiu a elaboração de um novo produto, com potencial de mercado para a comercialização e de valor nutricional agregado.

\section{Agradecimentos}

Os autores agradecem ao Centro Universitário Estácio do Ceará, pela infraestrutura laboratorial utilizada na realização desse estudo e a Universidade Federal do Ceará, pelo essencial auxílio.

\section{Referências}

Almeida, I. S. (2016). Avaliação bromatológica da farinha de sementes de jaca (Artocarpus heterophyllus Lam.) como possível substituinte da aveia para elaboração de barras de cereais (Trabalho de conclusão de curso). Faculdade Maria Milza, Governador Mangabeira.

Brasil. Ministério da Saúde. Agência Nacional de Vigilância Sanitária. (2005, setembro 23). Regulamento técnico para produtos de cereais, amidos, farinhas e farelos (Resolução RDC, $n^{\circ} 263$, de 22 de setembro de 2005). Diário Oficial da União, Brasília.

Carmo, A. S., Almeida, J. M., \& Holanda, H. D. (2017). Avaliação sensorial de biscoitos tipo cookies utilizando a farinha de manga tommy atkins (Mangifera indica L.). Revista Brasileira de Agrotecnologia, 7(2), 288-293. Recuperado em 2 de setembro de 2017, de http://www.gvaa.com.br/revista/index.php/REBAGRO/article/view/5197/288-293

Cecchi, H. M. (2003). Fundamentos teóricos e práticos em análise de alimentos (2. ed. rev.). Campinas: UNICAMP.

Chaves, M. A., Mendonça, C. R. B., Borges, C. D., \& Porcu, O. M. (2013). Elaboração de biscoito integral utilizando óleo e farinha da polpa de abacate. Boletim do Centro de Pesquisa e Processamento de Alimentos, 31(2). http://dx.doi.org/10.5380/cep.v31i2.34844

Dutcosky, S. D. (2013). Análise sensorial de alimentos (pp. 307-309). Curitiba: PUC Press.

Ferrari, R. A. (2015). Caracterização físico-química do óleo de abacate extraído por centrifugação e dos subprodutos do processamento. Brazilian Journal of Food Technology, 18(1), 79-84. http://dx.doi.org/10.1590/1981-6723.4014

Galindo, C. O. (2014). Análise sensorial de produtos elaborados a base de partes não convencionais de frutas (Trabalho de conclusão de curso). Universidade Tecnológica Federal do Paraná, Curitiba.

Guimarães, P. B., \& Capobiango, M. (2017). Determinação da composição centesimal da farinha obtida a partir da farinha do caroço de abacate. In Anais do III Congresso Nacional de Alimentos e Nutrição e VI Congresso Nacional de Alimentação e Nutrição. Ouro Preto: PUC Minas.

Instituto Adolfo Lutz - IAL. (2008). Métodos físico-químicos para análise de alimentos (4. ed.). São Paulo: IAL.

Lermen, F. H., Matias, G. S., Modesto, F. A., Roder, R., \& Boiki, T. J. P. (2013). Teste de consumidores e análise de aparência, sabores e cores para o desenvolvimento de novos produtos: O case do Projeto de Broinhas de Milho Saboreadas (Dissertação de mestrado). Programa de Pós-graduação em Engenharia de Produção, Universidade Estadual do Paraná, Campo Mourão.

Melo, M. L. N., Costa, T. S., Sousa, C. A. B., \& Marsiglial, W. I. M. L. (2012). Caracterização físico-química do caroço de abacate (Persea americana, Mill). In Anais do Encontro Nacional de Educação, Ciência e Tecnologia. Campina Grande: Universidade Estadual da Paraíba.

Menezes, J. D. S. (2013). Produção de goma xantana a partir da bioconversão de resíduos de malte de cervejaria por Xanthomonas campestris pv. campestris IBSBF 1866 (Tese de doutorado). Universidade Federal de Sergipe, Aracaju.

Moura, F. A., Spier, F., Zavareze, E. R., Dias, A. R. G., \& Elias, M. C. (2010). Biscoitos tipo "cookie" elaborados com diferentes frações de semente de abóbora (Curcubita maxima). Alimentos e Nutrição, 21(4), 579-585.

Nascimento, M. R. F., Souza, V. F., Marinho, A. F., Ascheri, J. L. R., \& Meleiro, C. H. (2016). Composição centesimal e minerais de farinha do caroço de abacate (Persea gratissima, Gaertner f.). In Anais do XXV Congresso Brasileiro de Ciência e Tecnologia de Alimentos; X CIGR Session VI International Technical Symposium. Gramado: SBCTA Regional. Recuperado em 25 de setembro de 2017, de https://www.alice.cnptia.embrapa.br/bitstream/doc/1057908/1/67.pdf

Osborne, D. R., \& Voogt, P. (1986). Análisis de los nutrientes de los alimentos (258 p.). Zaragoza: Acribia.

Queiroz, A., Rocha, R. F. J., Garruti, D. S., Silva, A. P. V., \& Araújo, I. M. S. (2017). Elaboração e caracterização de cookies sem glúten enriquecidos com farinha de coco: Uma alternativa para celíacos. Brazilian Journal of Food Technology, 20(0), e2016097. http://dx.doi.org/10.1590/1981-6723.9716

Rigo, M., Bezerra, J. R. M. V., Rodrigues, D. D., \& Teixeira, A. M. (2017). Avaliação físico-química e sensorial de biscoitos tipo cookie adicionados de farinha de bagaço de malte como fonte de fibra. Ambiência, 13(1), 47-57. Recuperado em 2 de setembro de 2017, de http://revistas.unicentro.br/index.php/ambiencia/article/download/3888/pdf

Rodrigues, M. G. G., Santos, E. F., Sanches, F. L. F. Z., Novello, D., Manhami, M. R., \& Neumann, M. (2014). Desenvolvimento de cookies adicionados de farinha de yacon (Smallanthus sonchifolius): Caracterização química e aceitabilidade sensorial entre portadores de Diabetes Mellitus. Revista do Instituto Adolfo Lutz, 73(2), 219-225. Recuperado em 25 de outubro de 2017, de http://revistas.bvs-vet.org.br/rialutz/article/view/27460/28763

Rosa, P. A., Santos, M. M. R., Candido, C. J., Schwarz, K., Santos, E. F., \& Novello, D. (2017). Elaboração de cookies com adição de farinha de casca de batata: Análise físico-química e sensorial. Evidência-Ciência e Biotecnologia, 17(1), 33-44. http://dx.doi.org/10.18593/eba.v17i1.13357 
Silva, I. F. B., Sousa, B. A. A., Bezerra, A., Silva, W. A., \& Medeiros, G. C. A. (2012). Elaboração de biscoitos tipo cookies com farinha de resíduos do processamento de polpa de acerola. In Anais do Encontro Nacional de Educação, Ciência e Tecnologia. Campina Grande: Universidade Estadual da Paraíba.

Soares, J. M., Santos, M. M. R., Candido, C. J., Santos, E. F., \& Novello, D. (2017). Cookies adicionados de farinha de jatobá: composição química e análise sensorial entre crianças. Revista Brasileira de Pesquisa em Saúde, 18(3), 74-82.

Storck, C. R., Nunes, G. L., Oliveira, B. B., \& Basso, C. (2013). Folhas, talos, cascas e sementes de vegetais: composição nutricional, aproveitamento na alimentação e analise sensorial de preparações. Ciência Rural, 43(3), 537-543. http://dx.doi.org/10.1590/S0103-84782013000300027

Tango, J. S., Carvalho, C. R. L., \& Soares, N. B. (2004). Caracterização física e química de frutos de abacate visando a seu potencial para extração de óleo. Revista Brasileira de Fruticultura, 26(1), 17-23. http://dx.doi.org/10.1590/S010029452004000100007 